\title{
A ATUAÇÃO DOS CONSELHOS GESTORES DE POLÍTICAS PÚBLICAS NA DOUTRINA DA PROTEÇÃO INTEGRAL INFANTO ADOLESCENTE
}

\author{
Cleide Aparecida Rodrigues Gomes Fermentão ${ }^{1}$ \\ Karyta Muniz de Paiva Lessa ${ }^{2}$
}

Resumo: O presente artigo objetiva analisar as transformações dos trinta anos de Estatuto da Criança e do Adolescente, a doutrina da proteção integral, a ação dos conselhos gestores de políticas públicas e sua eficácia atual. Para atender estes problemas, utiliza-se a revisão bibliográfica como método, pesquisa em leis, artigos, livros e dissertações, com objetivo de compreender o tema em questão e o que se tem feito de fato no Brasil. Verificou-se que as políticas públicas existentes precisam se fortalecer com apoio da sociedade civil, afim de alcançarem uma verdadeira proteção integral das crianças e adolescentes, enquanto vulneráveis.

Palavras-chave: Criança e adolescente; Conselho de gestores; Estatuto da Criança e do Adolescente; Políticas públicas; Proteção Integral

\section{THE PERFORMANCE OF PUBLIC POLICY MANAGEMENT COUNCILS IN THE DOCTRINE OF INTEGRAL PROTECTION FOR CHILDREN ADOLESCENTS}

\begin{abstract}
This article aims to analyze the transformations of the thirty years of the Child and Adolescent Statute, the doctrine of integral protection, the action of public policy management councils and their current effectiveness. To address these problems, bibliographic review is used as a method, research on laws, articles, books and dissertations, in order to understand the topic in question and what has actually been done in Brazil. It was found that existing public policies need to be strengthened with the support of civil society, in order to achieve true comprehensive protection for children and adolescents, while vulnerable.
\end{abstract}

Keywords: Child and adolescent; Management council; Child and Adolescent Statute; Public policy; Comprehensive Protection

\section{INTRODUÇÃO}

\footnotetext{
${ }^{1}$ Pós doutora em hermenêutica jurídica pela UNISINOS-Universidade Vale do Sino - RS; Doutora em direito das relações sociais pela Universidade Federal do Paraná - UFPR; Mestre em Direito Civil pela Universidade Estadual de Maringá - UEM; Docente no Programa de Mestrado e doutorado da UNICESUMAR, Pesquisadora do ICETI. Membro da IBDFAM e do IAP - Instituto dos advogados do Paraná. Advogada. Orcid: https://orcid.org/0000-0002-7121-5565. E-mail: cleidefermentao@gmail.com.

${ }^{2}$ Mestranda em Ciências Jurídicas pelo programa de mestrado e doutorado da Universidade UniCesumar. Bolsista do Programa de Suporte à Pós-Graduação de Instituições de Ensino Particulares (PROSUP/CAPES). Membro do grupo de Pesquisa "Proteção Integral da Pessoa: Interações dos Direitos Humanos, dos Direitos Fundamentais e dos Direitos da Personalidade"; Especialista em Ciência Política. Orcid: https://orcid.org/00000002-2627-9017. E-mail: karytamp@gmail.com.
} 
As crianças e os adolescentes no Brasil em tempos contemporâneos continuam se destacando em sua vulnerabilidade. Ao analisar a responsabilidade que a família tem em proporcionar às crianças e aos adolescentes o completo desenvolvimento e proteção da sua dignidade; o Estado em garantir a proteção integral e a efetividade dos benefícios contidos em Lei; e toda a sociedade possui, na proteção e garantia de direitos destas pessoas, sujeitos de direitos, vê-se uma falta de comunicação entre tais responsáveis e portanto, o objetivo geral deste artigo é analisar e traçar métodos efetivos na proteção integral da criança por meio de uma "rede amiga" do Estado, família e sociedade.

A presente pesquisa buscará analisar as seguintes questões: Como alcançar a efetivação da Doutrina da Proteção Integral? Como reeducar a sociedade em relação às práticas autoritárias versus autoridade paterna? Como o trabalho em rede pode auxiliar o Estado, a família e a sociedade na proteção integral e efetiva das crianças e dos adolescentes? É possível alcançar a justiça e garantir os direitos às crianças e adolescentes brasileiras nesta nova década?

Detalhar-se-á e verificar-se-á quem são as crianças e adolescentes do início da década de 2020; analisar-se-á a incontestável vulnerabilidade infanto adolescente na sociedade brasileira; e por fim; a promoção da tríade responsabilidade compartilhada das três áreas proposta pela legislação: família, sociedade e Estado e os seus papéis em promover a dignidade da pessoa humana entre as crianças e adolescentes por meio de políticas públicas, em especial pelos conselhos gestores de políticas públicas.

Examinar-se-á neste artigo a investigação baseada no método hipotético dedutivo, pois será realizada uma pesquisa bibliográfica e também uma análise quantitativa de livros, doutrinas e leis. A escolha do método se deu pela presença de grandes informações que se pode extrair de tais bibliografias, principalmente pela força vinculante que este tema possui no Brasil e o poder de efetivação dos direitos da personalidade no âmbito jurídico interno, quando o sujeito de direito são as crianças e adolescentes.

Para responder a problematização, no primeiro capítulo, buscar-se-á traçar o perfil da criança e do adolescente, em breve evolução histórica da família, bem como o início do reconhecimento da etapa da vida chamada adolescência, como a ONU pode ajudar aos países, em especial o Brasil, a desenvolver proteção constitucional a eles e como proceder diante de uma sociedade de consumo que acaba por atingir os mais novos e vulneráveis.

Em segundo momento, compreender-se-á sobre a doutrina da proteção integral da criança e do adolescente e de que maneira ao promulgar este princípio, a Constituição Federal 
de 1988 determina espera que a família, a sociedade e o Estado ajam de forma eficaz e efetiva em proteção da dignidade infanto adolescente. E por fim, no terceiro e último capítulo, destacar-se-á como os conselhos gestores de políticas públicas foram estabelecidos, de que forma se tornaram autônomos e como a sociedade civil tem colaborado com os trabalhos em prol do bem maior da criança e do adolescente.

\section{A CRIANÇA E O ADOLESCENTE NA CONTEMPORANEIDADE}

As crianças e os adolescentes são pessoas que vivem o momento de sua jornada, que estão em desenvolvimento, seja do ponto de vista intelectual, físico, emocional, psicológico, religioso, etc.

São tão sujeitos de direitos quanto os adultos, e estão em pleno desenvolvimento, todavia, as crianças e os adolescentes possuem direitos oriundos de sua condição de ser humano em desenvolvimento (PONTES JUNIOR, 1993). Pelos valores hodiernos, é inadmissível que as crianças e adolescentes sofram algum tipo de opressão e violências, porém isto pode variar com a cultura de cada local.

Sob um olhar histórico, na Roma Antiga, o pai tinha absoluto poder sobre os seus filhos, inclusive a opção de fazer com que se tornassem escravos ou tirar suas vidas, tanto que durante o tempo de Augusto $^{3}$ os recém-nascidos eram expostos nas portas do palácio imperial, matando-se os não eleitos, prática que cumpria as funções atuais do aborto" (MENDEZ, 1991, p. 47). Já na Idade Média, por exemplo, a criança passou por uma invisibilidade, sendo totalmente excluída da sociedade (VERONESE; RODRIGUES, 2001).

A adolescência passou a ser reconhecida no momento em que se elevou à escolarização, na qual, as crianças - em formação - foram separadas dos adultos e, portanto, resguardada do trabalho (ARIÈS, 1986), inicialmente nas classes mais altas e posteriormente nas classes mais baixas. Sob o olhar ocidental, foi na década de 1980 que se instaurou uma maior preocupação com os adolescentes (ARIÈS, 1986) No Brasil foi neste período que a matéria de direitos das crianças e os adolescentes tiveram o início de mudanças, pois até então, eles também viviam em condições de extrema exclusão social, desamparo e falta de tutela. A Assembleia Geral realizada pela ONU, concebeu a Convenção dos Direitos da

\footnotetext{
${ }^{3}$ Augusto é considerado pela história, o criador do Império Romano e também o primeiro Imperador Romano, período datado de $27 \mathrm{aC}$ até $14 \mathrm{dC}$.
} 
Criança, e também culminou os direitos das crianças dos países signatários, como é o caso do Brasil, que a ratificou logo em seguida (SANTOS, 2006).

Na sociedade moderna da criança ao jovem é estabelecido o status de dependência, conforme afirma Durkhein (1970), a criança necessita ser submetida aos costumes, às normas, aos valores sociais e também aqueles significados tidos como símbolos socialmente constituídos. Em todos os períodos do desenvolvimento da criança, percorre fases que vai da pré-social até a social e o que virá a ser está disposto, categorizado e também predito (Wallon, 1968; Piaget, 1976; Vygotsky, 1993).

Em tempos contemporâneos é diferente da época moderna. Atualmente existem outros meios de relações familiares, bem como o processo de socialização. Existe um enorme anseio para satisfação de vontades e desejos, de forma rápida por meio do consumismo exacerbado. Os acessos a informações podem ser alcançados de forma desenfreada, inclusive, sem a supervisão dos pais e responsáveis, uma vez que, a aproximação aos smartphones, televisores, etc., são empregados cada vez mais cedo na vida das crianças e adolescentes.

A aproximação aos mais variados métodos de comunicação e informações possibilita às pessoas infanto juvenis uma entrada precoce ao mundo da violência, sexo, drogas e atos ilícitos, fazendo com que informações que as crianças poderiam obter apenas dentro das salas de aulas, a título de conhecimento e informação, por meios dos professores, sejam passadas de forma atropelada e sem filtro. $\mathrm{O}$ que tem produzido uma preocupação no cenário acadêmico, pois ainda em tempos contemporâneos, as relações familiares vão se apropriando do que lhes é oferecido na cultura local e dos valores da sua sociedade local, seja ele onde for (Simmel, 1986; Montandon 2001). Daí surge a urgente necessidade de se esclarecer a responsabilidade e a indispensabilidade de se trabalhar e analisar a família, a sociedade e também o Estado.

A escravização por uma cultura que enaltece o consumo, explicada por Bauman, onde as pessoas querem aquilo que está pronto para o uso, ou que causa prazer passageiro, que é fácil, ou que caso não goste, pode-se ter o dinheiro de volta, "a promessa de aprender a arte de amar é a oferta (falsa, enganosa, mas que se deseja ardentemente que seja verdadeira) de construir a 'experiência amorosa' à semelhança de outras mercadorias, [...] prometem desejo sem ansiedade, esforço sem suor e resultados sem esforço" (2004, p.18). Muito embora muitos sejam influenciados por filmes de Hollywood, com finais felizes, vidas fáceis e todos são obrigados piamente a satisfazer os interesses do personagem principal. A vida real é diferente, existe uma coletividade, onde um ajuda o outro e cada um é protagonista de sua própria história. 


\section{FAMÍLIA, ESTADO E SOCIEDADE E A DOUTRINA DA PROTEÇÃO INTEGRAL}

A promulgação da Constituição da República Federativa do Brasil de 1988 efetivou a alteração normativa sobre os deveres provenientes do poder familiar. Juntamente com este aspecto, o Direito da Criança e do Adolescente passou a ser tutelado com outros olhos. As crianças e adolescentes passam a ser sujeitos de direitos e a doutrina da proteção integral passa a ser fundamental nesta seara, promovendo uma maior proteção a eles.

A Lei 8.069/90, Estatuto da Criança e do Adolescente em seu artigo $4^{\circ}$, prevê o dever da família, da comunidade e do poder público de "assegurar, com absoluta prioridade, a efetivação dos direitos referentes à vida, à saúde, à alimentação, à educação, ao esporte, ao lazer, à profissionalização, à cultura, à dignidade, ao respeito, à liberdade e à convivência familiar e comunitária" (BRASIL, 1990), de igual modo também a Emenda Constitucional 65/2010, institui o artigo 227 na Constituição Federal que acrescenta sobre os direitos da criança e do adolescente: "à dignidade, ao respeito, à liberdade e à convivência familiar e comunitária, além de colocá-los a salvo de toda forma de negligência, discriminação, exploração, violência, crueldade e opressão" (BRASIL, 1988).

A criança e o adolescente gozam de direitos inerentes à pessoa humana, como os direitos fundamentais, para que lhes sejam garantidos seu pleno desenvolvimento como pessoa, nos mais variados âmbitos: físico, social, moral, entre outros. Antes de adentrar neste aspecto, sobre a proteção integral, faz-se necessário discorrer sobre os direitos da personalidade e o princípio da dignidade da pessoa humana.

Os direitos humanos definidos em tratados e convenções internacionais, recepcionados pela Constituição Federal de 1988, transformaram-se em direitos fundamentais, possuindo aplicabilidade imediata. A expressão direitos fundamentais no entendimento de Sarlet (2012, p. 29), deve ser "aplicada para aqueles direitos do ser humano reconhecidos e positivados na esfera do direito constitucional positivo de determinado Estado, ao passo que a expressão 'direitos humanos' guardaria relação com os documentos de direito internacional”.

Neste mesmo entendimento, Canotilho (2003, p. 393) defende que "os direitos humanos, são válidos para todos os povos intertemporais e universal, enquanto que os direitos fundamentais, são os direitos instituídos pelas leis imanes dos países, garantidos por uma ordem jurídica concreta, por isso, limitados pelo espaço e pelo tempo”, e Bobbio (1992, p. 16) 
compreende que "o verdadeiro estado do homem não é o estado civil, mas o natural, ou seja, o estado de natureza no qual os homens são livres e iguais, sendo o estado civil uma criação artificial, que não tem outra meta além da de permitir a mais ampla explicitação da liberdade e da igualdade naturais".

Algumas características do homem como sua personalidade e caráter, por exemplo, são parâmetros para que haja uma hierarquia dos valores. O direito é um valor e permanece no que se chama de estado do imaginário até que a norma jurídica o incorpore, trazendo à tona sua vigência e efetividade (FERMENTÃO, 2011, p.624), na relação entre o valor e o direito, tem-se uma intimidade que visualiza facilmente pela perspectiva ontológica, e sempre que valores surgem, o direito é enriquecido. Este é composto por finalidades, tradições, significados, valores, etc. Ambos nascem e principiam do corpo social e só assim fazem quando são instigados por inevitabilidade exposta. Importante atentar que "se os valores se apoiam no consenso são mutáveis de acordo com o grupo social, o tempo e o espaço" (FERMENTÃO, 2011, p. 624).

É no decorrer do tempo que os direitos vão surgindo baseado nos valores, garantindo-os e protegendo-os. No tocante aos direitos da personalidade não é diferente. Os valores que compreendem a personalidade humana são tutelados pelo direito da personalidade, igualmente a quaisquer outras privações humanas. $\mathrm{O}$ valor humano é inerente ao homem, intrínseco a ele, portanto para estruturar moralmente e eticamente, surge o valor do direito, seguido do valor justiça, cujo âmago é a igualdade. A finalidade última é a justiça, sendo que a base da ordem jurídico normativa é o valor e o direito é o meio da justiça (FERMENTÃO, 2011, p. 625).

Segundo Kant, "no reino dos fins tudo tem um preço ou uma dignidade" ou "quando uma coisa tem um preço, pode-se pôr em vez dela qualquer outra como equivalente; mas quando uma coisa está acima de todo preço, e, portanto, não permite equivalente, então tem ela dignidade" (KANT, 1980, p. 77).

É possível considerar inúmeras dimensões sobre a dignidade como: ontológica, comunitária ou social, histórico-cultural, e também a negativa e prestacional. A primeira, quer dizer que a dignidade é algo inerente ao ser humano, a segunda é que todas as pessoas são iguais em dignidade e direito, a terceira, ele entende sendo inequívoca, uma vez que o conceito está sempre em um processo de construção em si, e também para responder às necessidades sociais, e por fim, leva-se em consideração que a dignidade pode ser manifesta ao mesmo tempo com o que se chama de autonomia da pessoa, ou em outras palavras, o que 
se entende de direito de autodeterminação para tomada de decisões que é própria à pessoa (SARLET, 2007, p.30-33).

Helmut Coing compreende o princípio da dignidade da pessoa humana de acordo com duas concepções: no primeiro momento imputa-se que a proteção da pessoa humana no que tange à sua integridade, ou seja, serve de impedimento contra práticas ou ofensas físicas e psíquicas contra o ser humano, protegendo de forma geral a sua vida; em segundo momento diz respeito à expressão do direito do ser humano ser respeitado como ser intelectual, que representa então a garantia do direito à autodeterminação, ir e vir, escolher onde viver, etc. (apud SZANIAWSKI, 2005, p.140).

O primeiro e último fundamento da pessoa, é o princípio da dignidade humana, que guarda na vida e na morte os direitos individuais, uma vez que além de ser considerado um supra princípio, também é o mais importante de todo sistema. O advento da promulgação da Constituição Federal de 1988, contou com a instauração de inúmeros valores e princípios, o que trouxe um novo tempo para uma nova ordem jurídica (MOARES, 2006). A dignidade da pessoa humana foi eleita como fundamento do próprio Estado Democrático de Direito. A tutela integral e primordial da pessoa trouxe alteração paradigmática, possuindo valor constitucional, sendo princípio fundamental e tido como o telos de todo o sistema (CANTALI, 2009, p.86).

A raiz da dignidade da pessoa humana consiste na superação e no domínio do homem sobre a sua própria existência. Assim, ela pode ser entendida como a superioridade do ser humano sobre àqueles que carecem de razão, sobre os irracionais, pelo que, Segundo Santo Agostinho, sobre esta mente racional, somente há o Criador, que o criou a sua imagem e semelhança (PÉREZ, 1986, p.)

O fundamento tido como valor fonte do sistema constitucional confere a dignidade da pessoa humana uma "unidade axiológico-normativa ao sistema constitucional" (MARTINS, 2003 p. 63), permitindo que assim, a Constituição Federal de 1988 possa prever inúmeros direitos fundamentais. O princípio da dignidade da pessoa humana, inserido no ordenamento jurídico brasileiro, deve ser utilizado como instrumento norteador da proteção dos direitos da personalidade e das relações familiares, pautadas na contemporaneidade pelo afeto entre os seus integrantes

A tutela da dignidade deve realizar-se em relação a todos os aspectos, sem, porém, que se deva traduzir na mesma situação de vantagem e na noção de direito subjetivo. A diversidade dos interesses fundamentais do homem não se traduz em uma pluralidade de 
direitos fundamentais diversificados por conteúdo e por disciplina. O que releva é o valor da pessoa unitariamente entendida" (PERLINGIERI 2002. p. 159).

O direito geral da personalidade resguarda o homem em toda e qualquer circunstância, levando em consideração que a proteção de tal tutela tem como objetivo de preservar, em todas as situações, a dignidade da pessoa humana (PERLINGIERI, 1972, p.186). Com a valorização da pessoa humana, percebe-se que a conceituação de personalidade sofreu mudanças, não apenas em relação a sua capacidade de ser sujeito de direitos, ou seja, a personalidade deve ser considerada como uma expressão intrínseca e da própria pessoa, ou seja, consequentemente relacionada à pessoa, logo também ao valor.

No entendimento da Doutrina da Proteção Integral, existe uma corresponsabilidade entre a família, a sociedade e o Estado para que os direitos da criança e do adolescente sejam tutelados, sempre visando assistir a estes, no seu melhor interesse. Tal doutrina, veio para substituir a doutrina passada, dita por Sistema Menorista, na qual os filhos não passavam de propriedades dos pais, herança romana (COSTA, 1993).

A família e as crianças foram as principais prejudicadas por este sistema, pois, a família de um lado se via à mercê do Poder Judiciário, que se impunha sobre a família de forma acirrada. A legislação da época "ao zelar pela infância abandonada e criminosa, prometia extirpar o mal pela raiz, livrando a nação de elementos vadios e desordeiros, que em nada contribuíram para o progresso do país" (RIZZINI, 2006, p.139)

A efetivação desses direitos deve ocorrer com base em novas políticas públicas, atividades e tudo o que possa contribuir para que sejam concretizados e as crianças e adolescentes sejam tuteladas, objetivando sempre a sua dignidade humana. Tais meios precisam atingir tanto a sociedade, quanto o Estado e de igual modo todas as famílias. compreendendo que a Doutrina em questão inclui a criança e o adolescente como sujeitos de direitos fundamentais, vindo tanto a lutar contra negligência dos pais, como tratar outros problemas que atingem os menores.

É no seio familiar que deverá acontecer um ambiente que oportunize tanto às crianças, quanto aos adolescentes a sua plena promoção emocional, cognitiva, física, etc., segundo Rosane Leal da Silva

Os pais devem estar atentos às suas demandas, o que algumas vezes significa exercitar a habilidade da escuta atenta; em outros momentos exigirá que o adulto ocupe o espaço de fala que lhe é próprio, impondo limites, corrigindo rumos ou apontando caminhos que facilitem ou minimizem um problema 
que aos olhos do adolescente parece intransponível. Cada um desses gestos revela a mais pura expressão de cuidado. (SILVA, 2009, p. 44-45)

A família é a parte direta nessa corresponsabilidade, tanto na promoção, quanto na prevenção de todos os direitos que dizem respeito às crianças e aos adolescentes. Caminhar e doar-se, durante esta jornada, por estas pessoas em desenvolvimento diz respeito a uma nova configuração dentro dos seios familiares, e isto se estende também sobre a função da sociedade e do Estado, configurando o sistema de garantia de direitos da criança e do adolescente, sendo ele lógico e organizado (CUSTÓDIO; VERONESE, 2009).

Este sistema de garantia de direitos presume que os princípios norteadores destacados no aspecto da dissociação político-administrativa nas três esferas do governo, na predisposição do que tange a instituição, e também conjectura de um trabalho em "rede" e de cooperações entre todos que possam ajudar, a doutrina jurídica de proteção integral pretende alcançar a "garantia de que toda Criança ou Adolescente sejam efetivos beneficiários de políticas sociais básicas, complementares ou assistenciais. Porém, sem assistencialismo, como também de ações político-administrativas, de mecanismos jurídico-processuais, de programas de atendimento" (LIMA, 2001, p. 177).

A rede de atendimento é composta pelos Conselhos de Direitos da Criança e do Adolescente, Conselhos Tutelares, Ministério Público, Varas da Infância e do Adolescente, Delegacias de Defesa da Criança e do Adolescente, Organizações não governamentais com o objetivo geral de assegurar que haja desenvolvimento pessoal pleno para todas as crianças e os adolescentes. A Constituição Federal de 1988 determinou que os Municípios passassem a ser mais ativos e autônomos nesta alçada, e também maiores poderes de decisão (DOWBOR, 2006), assim, cada município tem total liberdade para se organizar dentro de suas necessidades e realidades, contando com o apoio da sociedade civil e então trabalhar contra estas dificuldades frente às situações infanto juvenis. O sistema que amplia as garantias do Direito da Criança e do Adolescente é incumbido quanto a transição das velhas e antigas políticas sociais truncadas, burocráticas e completamente centralizadoras.

\section{A VULNERABILIDADE INFANTO ADOLESCENTE E OS CONSELHOS GESTORES DE POLÍTICAS PÚBLICAS}


Todos os dias as crianças e adolescentes sofrem transgressões de seus direitos, principalmente porque tanto a família como o Estado, e também a sociedade, não se apropriaram da roupagem sociojurídica e também política que são tutelados pelo Direito da Criança e do Adolescente. Se tais direitos tivessem eficácia a realidade seria totalmente diferente, afastaria os riscos e a vulnerabilidade infanto juvenil existente.

$\mathrm{O}$ que tornam as crianças e adolescentes vulneráveis é a impossibilidade física e emocional de decidirem a vida, de sobreviverem sozinhos, são dependentes porque precisam de proteção para a sobrevivência e para o desenvolvimento. Necessitam de amparo e cuidado relacional com os adultos à sua volta. E isso, faz com o que a família, a sociedade e o Estado, sejam amplamente corresponsáveis por cada um. Não se trata apenas de condição social, que embora seja um dos motivos principais, ainda há outras condições, envolvendo todas as áreas em que as crianças e adolescentes são submetidas diariamente, tanto na esfera pública, como privada.

As condições que estão relacionadas com a vulnerabilidade infanto juvenil são: fatores em relação ao dinamismo na seara familiar, fatores em relação ao trabalho infantil, ou aos riscos em relação à saúde, fatores em relação à moradia, etc. A preocupação com o Estado de bem-estar Social, possui a prevenção como fator primordial, embora há quem acredite que com o passar dos anos, é possível que tenha tido algumas modificações (ABRAMOVAY, 2002).

A proteção integral requer atenção integral e sua doutrina inaugura grande avanço na elaboração de políticas públicas. A gestação democrática brasileira é proveniente da democracia liberal, fundamentada em princípios do sistema liberal, é se espera que sua atividade seja por meio da representação popular, ou seja, o próprio povo é quem elege quem quer que os represente. Desta forma, essas duas primeiras décadas do século XXI tem sido gerido pela vontade de todos que é implementada da deliberação de cada um, versus a deliberação geral em relação ao bem comum (CARVALHO, 2016). Se o bem comum é relevado em importância quando se reflete em democracia, então é mister destacar que deveria haver o fortalecimento do âmbito público, no que tange ao interesse comum.

Para que haja formulação de políticas públicas gerais é preciso que haja uma teoria crítica do poder e do Estado, então a "implementação de políticas públicas de promoção humana [...]" possui objetivo de "assegurar à satisfação das necessidades humanas" (MOTTA; DANTE, 2016, p. 348-349). As crianças e os adolescentes, ao serem vistas e consideradas sujeitos de direitos, remete ao fato de que estes direitos devem ser respeitados e 
no dia a dia, isto pode ser visto com a atenção que os indivíduos da sociedade venha dar a este assunto. Ou melhor, como a sociedade e o Estado tem colocado as crianças e os adolescentes como prioridades. A organização de políticas públicas no Brasil democrático indica relação intrínseca com ações da sociedade, tanto no processo como na elaboração da legislação complementar (AVRITZER, 2006).

O desenvolvimento de uma relação de corresponsabilidade para a efetivação dos direitos das crianças e adolescentes é necessário. Esta relação pode ser caracterizada por uma rede, com intuito de alcançar um fortalecimento do trabalho "a criação de redes com focos bem delimitados, como o dos maus-tratos, ou, mais especificamente, abuso e exploração sexual, e o da situação de rua" (RIZZINI, 2006, p. 114).

A Constituição Federal de 1988 é minuciosa e redundante na previsão de direitos e situações subjetivos de vantagens das crianças e adolescentes, especificando em relação a eles direitos já consignados para todos em geral (SILVA, 2009, p. 851), juntamente com ela, o Estatuto da Criança e do Adolescente também estabelece um sistema de garantia de direitos, no qual as políticas não são um fim em si mesmas, mas configuram estratégias de ação para os operadores do sistema . (CUSTÓDIO; VERONESE, 2009, p. 143). Isto é resultado da tentativa de efetivar os direitos fundamentais e da personalidade em prol da promoção do desenvolvimento infanto adolescente.

O Estatuto da Criança e do Adolescente trouxe em seu artigo 87 linhas de ação para que políticas públicas sejam elaboradas com o intuito de promover o desenvolvimento e dignidade ${ }^{4}$, dentre elas pode se destacar as políticas sociais básicas, e também vários serviços,

\footnotetext{
4 Art. 87. São linhas de ação da política de atendimento:

I - políticas sociais básicas;

II - políticas e programas de assistência social, em caráter supletivo, para aqueles que deles necessitem

II - serviços, programas, projetos e benefícios de assistência social de garantia de proteção social e de prevenção e redução de violações de direitos, seus agravamentos ou reincidências; (Redação dada pela Lei $\mathrm{n}^{\circ}$ 13.257, de 2016)

III - serviços especiais de prevenção e atendimento médico e psicossocial às vítimas de negligência, maus-tratos, exploração, abuso, crueldade e opressão;

IV - serviço de identificação e localização de pais, responsável, crianças e adolescentes desaparecidos; $\mathrm{V}$ - proteção jurídico-social por entidades de defesa dos direitos da criança e do adolescente. VI - políticas e programas destinados a prevenir ou abreviar o período de afastamento do convívio familiar e a garantir o efetivo exercício do direito à convivência familiar de crianças e adolescentes; (Incluído pela Lei $\mathrm{n}^{\circ}$ 12.010, de 2009) Vigência

VII - campanhas de estímulo ao acolhimento sob forma de guarda de crianças e adolescentes afastados do convívio familiar e à adoção, especificamente inter-racial, de crianças maiores ou de adolescentes, com necessidades específicas de saúde ou com deficiências e de grupos de irmãos. (Incluído pela Lei n ${ }^{\circ} 12.010$, de 2009) Vigência
} 
programas, projetos e benefícios com intuito de proteção social e prevenção e redução de violação de direitos.

Destaca-se os Conselhos Gestores de Políticas Públicas, constituído tanto pela sociedade como pelo Estado que tem o objetivo de propor diretrizes das políticas públicas, bem como fiscalizar, controlar, deliberar, entre outros. São sempre autônomos em suas decisões e permanentes, representam órgãos de gestão pública e que possui relação e vínculo com o Executivo, embora não seja subordinado a ele (NAHRA, 2007). É visto como um novo padrão de relação entre Estado e sociedade, criando novas formas de contrato social, por meio da ampliação da esfera social pública (GOHN, 2004, p.66), pois se detecta uma descentralização administrativa e também um aumento e possibilidade que a sociedade possa participar de forma efetiva na gestão das políticas públicas. Bem como de instâncias de decisões e não de atendimento.

A possibilidade de participação de vários setores da sociedade, também representa diversos grupos sociais que figuram as mais diversas propensões. Isto não quer dizer, na prática, que existe um amplo Estado democrático, afinal esta tarefa é árdua e constante. De acordo com Dagnino (2002, p. 296-297):

Atribuir indiscriminadamente aos espaços de participação o papel de agentes funda- mentais na transformação do Estado e da sociedade, na eliminação da desigualdade e na instauração da cidadania, transformando as expectativas que estimularam a luta política que se travou pela sua constituição em parâmetros para sua avaliação, pode nos levar inexoravelmente à constatação do seu fracasso. Uma avaliação mais produtiva [...] deve partir do reconhecimento da complexidade desse processo e da diversidade dos contextos, envolvendo a multiplicidade de relações entre forças políticas onde ele se dá.

Destaca-se a necessidade de zelar por uma qualidade de participação com intuito de beneficiar apenas as crianças e os adolescentes, e não interesses políticos e econômicos. Pela finalidade de desvelar para que os direitos sejam protegidos, existe uma natureza emergencial na atuação desses conselhos para fortalecer uma cultura cidadã. Todavia, o que tem se percebido de acordo com estudos de caso, é que os conselhos não são conhecidos pela sociedade e faz com que falte participação de fato e muito menos exigências de prestações de conta (VIDAL, 2011; SANTOS JÚNIOR, AZEVEDO e RIBEIRO, 2004).

As políticas públicas podem ser tidas pelas formas de como ocorre a execução do que a Lei prevê no papel, sendo também ferramentas para que haja eficaz aplicação, depois de serem arquitetadas a partir do texto legal (KAUCHAKJE, 2007). Desta forma, é necessário 
que o gestor municipal, estadual ou federal - em se tratando de ações públicas para o desenvolvimento de programas - atenda às necessidades e protejam as crianças e adolescentes, sendo papel do gestor municipal elaborar todo um planejamento, levando em consideração a realidade local, levantando dados sobre o perfil médio infanto juvenil.

\section{CONSIDERAÇÕES FINAIS}

Diante do exposto, percebe-se que as formas de infância, adolescência e juventude vem sofrendo alterações dia após dia. O que, possivelmente uma geração nascida na década de 1980 passou, está anos luz atrasada do que a geração da década de 2020. Mesmo percebendo um acelerado processo de liberdade infanto-juvenil, a responsabilidade familiar permanece, em corresponsabilidade com a sociedade e o Estado.

Por se tratar de uma faixa etária em processos de desenvolvimentos nas mais variadas áreas, é importante ressaltar a vulnerabilidade que se encontra neles, inclusive dependência social, psicológica, financeira, etc. Portanto, para poder tutelar e resguardar os direitos infanto-juvenis para esta nova década, propõe-se considerar estes como atores sociais, buscando incentivá-los desde cedo a elaborar políticas para eles mesmos, ou para aqueles em situação de risco, que haja assistência coerente e realmente efetiva, bem como o seu acompanhamento durante períodos prolongados; a criação de hospitais infanto-juvenis, bem como casa de apoios, centros de ajuda psicológica para aqueles que passaram ou passam por abusos.

Também se percebeu que a partir da promulgação da Constituição Federal de 1988, em conjunto com a elaboração do ECA/90, a doutrina da proteção integral foi normatizada no Brasil, isto vem a significar que crianças e adolescentes passaram a ser vistos como sujeitos de direito, desta forma, esta última lei não é algo utópico, ou uma carta de quereres, mas sim normas com direitos garantidores.

Pela doutrina da proteção integral, todas as crianças e adolescentes são vistas como detentores de direitos e proteção por ser considerada uma pessoa em pleno desenvolvimento. Feito esta análise, passou-se a compreender sobre como os conselhos gestores de políticas públicas podem agir, representando o Estado e a sociedade civil, em ações que visam unicamente os infanto adolescentes. Todavia percebeu-se que grande parte das discussões são 
atrasadas por questões políticas e sociais, ou seja, os verdadeiros interesses dos que pretendem agir efetivamente, em grande parte, são para interesses pessoais ou aos grupos que pertencem.

Em resumo, compreender a fragilidade que existe, em conjunto com a vulnerabilidade, mas desenvolver para cada situação em específico, e realidade social de cada região, redes de apoio, onde a sociedade tem liberdade para a criação de políticas que auxiliem na proteção e efetivação da Doutrina Integral da Criança, onde o Estado - na figura do Município - permite a entrada da sociedade para tal, e a família aceite toda ajuda possível, sem jamais deixar de cumprir seu papel principal: formar e amar pessoas. E que os conselhos gestores possam cumprir suas funções na elaboração de políticas públicas que garantam o desenvolvimento saudável das crianças e adolescentes.

\section{REFERENCIAS}

ABRAMOVAY, M. et al. Juventude, violência e vulnerabilidade social na América Latina. Brasília: Unesco, 2002.

ARIÈS, Philippe. História social da infância e da família. Rio de Janeiro: Guanabara,1986.

AVRITZER, Leonardo. Reforma Política e Participação no Brasil. In: AVRITZER, Leonardo; ANASTASIA, Fátima (org.). Reforma Política no Brasil. Belo Horizonte: Editora UFMS, 2006.

BAUMAN, Zygmunt. Amor líquido: sobre a fragilidade dos laços humanos. Rio de Janeiro: Jorge Zahar, 2004.

BOBBIO, Norberto. A Era dos Direitos. Tradução: Carlos Nelson Coutinho. Rio de Janeiro: Campus, 1992.

BRASIL. Constituição (1988). Constituição da República Federativa do Brasil. Brasília, DF. Senado Federal. Disponível em:

http://www.planalto.gov.br/ccivil_03/Constituicao/Constituicao34.htm. Acesso em: 20 abr. 2020.

BRASIL. Lei no 8.069/90. Estatuto da Criança e do Adolescente. Disponível em: http://www.planalto.gov.br/ccivil_03/leis/18069.htm. Acesso em: 20 abr. 2020.

CANOTILHO, J. J. Gomes. Direito constitucional. 6. ed. Coimbra: Almedina, 2003.

CANTALI, Fernanda Borghetti. Direitos da personalidade: disponibilidade relativa, autonomia privada e dignidade humana. Porto Alegre, Livraria do Advogado, 2009. 
CARVALHO, R. F. de. A constituição do Estado brasileiro na tensão entre o domínio e a direção de classe: a educação como arena éticopolítica. In: VILAS BÔAS, J. P. S.; NETO, L. F.; PERIUS, O. (org.). Filosofia em Debate: questões de ética, educação e política.

Florianópolis: Néfiponline, 2016, p. 207-240. Disponível em:

https://www.scielo.br/scielo.php?script=sci_nlinks\&pid=S1414-

4980201900030045700013\&lng=en Acesso em: 15 abr. 2020.

COSTA, Antônio Carlos Gomes. De menor a cidadão: Notas para uma história do novo direito da infância e juventude no Brasil. Editora do Senado, 1993.

CUSTODIO, André Viana; VERONESE, Josiane Rose Petry. Crianças esquecidas: o trabalho infantil doméstico no Brasil. Curitiba: Multideia, 2009.

DAGNINO, E. (Org.). Sociedade civil e espaços públicos no Brasil. Rio de Janeiro: Paz e Terra, 2002.

DOWBOR, L. Redes de apoio ao desenvolvimento local. Disponível em:

$<$ https://dowbor.org/2006/09/redes-de-apoio-ao-desenvolvimento-local-uma-estrategia-deinclusao-produtiva-doc.html/> Acesso em: 12 fev. 2020.

DURKHEIM, E. Representações individuais e representações coletivas. 2.ed. Rio de Janeiro: Forense Universitária, 1970.

FERMENTÃO; SILVA. A tutela dos valores interiores e da consciência humana pelo direito da personalidade. Revista Jurídica Cesumar. Maringá, PR, v.11, n. 2, p. 615-632, 2011. Disponível em:

https://periodicos.unicesumar.edu.br/index.php/revjuridica/article/view/2078. Acesso em: 13 jul. 2019.

GOHN, Maria da Glória. Os conselhos municipais e a gestão urbana. In SANTOS JUNIOR, Orlando Alves dos. Governança democrática e poder local: A experiência dos conselhos municipais no Brasil. Rio de Janeiro: Revan, 2004.

KANT, Imannuel. Fundamentação da Metafísica dos Costumes. Tradução: Paulo Quintela. Lisboa: Ed.70, 1980.

KAUCHAKJE, Samira. Gestão pública de serviços sociais. Curitiba, IBEPX, 2007.

LIMA, Miguel M. Alves. O Direito da Criança e do Adolescente: fundamentos para uma abordagem principiológica. 2001. Tese (Doutorado em Direito) Programa de Pós-Graduação em Direito pela Universidade Federal de Santa Catarina, Florianópolis, 2001.

MARTINS, Flademir Jerônimo Belinati. Dignidade da Pessoa Humana: Princípio Constitucional Fundamental. Curitiba: Juruá, 2003.

MENDEZ, E. G. O novo Estatuto da Criança e do Adolescente: uma visão latinoamericana. Brasília: UnB, 1991. 
MORAES, Maria Celina Bodin de. A constitucionalização do direito civil e seus efeitos sobre a responsabilidade civil. Revista Direito, Estado e Sociedade, Rio de Janeiro, RJ, v. 9, n. 29, p 233-258, 2006. Disponível em: https://revistades.jur.puc-

rio.br/index.php/revistades/article/view/295/267 Acesso em: 30 out. 2019.

MOTANDON, C. Sociologia da infância: balanço dos trabalhos em língua inglesa.

Disponível em: <http://www.scielo.br/scielo.php?pid=S0100-

15742001000100002\&script=sci_abstract\&tlng=pt> Acesso em: 25 fev. 2020.

NAHRA, Clicia Maria Leite. A representação do executivo municipal nos conselhos gestores de políticas públicas. Disponível em:

http://lproweb.procempa.com.br/pmpa/prefpoa/observatorio/usu_doc/executivo_conselhos.pd f. Acesso em: 20 mar. 2020.

MOTTA, Ivan Dias da; DANTE, Caroline Rodrigues Celloto. A personalidade na biopolítica e a ideia de promoção humana. Revista Jurídica - UniCuritiba, Curitiba, PR, v. 3, n.44, p. 336-354, 2016. Disponível em:

http://revista.unicuritiba.edu.br/index.php/RevJur/article/view/1752 Acesso em: 15 abr. 2020.

PÉREZ, Jesus Gonçalez. La Dignidad de la persona. Madrid: Civitas, 1986.

PERLINGIERI, Pietro. La personsalità umana nell'orfinamento giuridico. Lovene, 1972.

PIAGET, Jean. Da lógica da criança à lógica do adolescente. São Paulo: Pioneira, 1976.

PONTES JÚNIOR, Felício. Conselho de direitos da criança e do adolescente. São Paulo: Malheiros, 1993

RIZZINI, Irene. Crianças e menores: do Pátrio Poder ao Pátrio Dever: um histórico da legislação para a infância no Brasil. In: RIZZINI, Irene; PILOTTI, Francisco (Org.) A arte de governar crianças: a história das políticas sociais, da legislação e da assistência à infância no Brasil. 2.ed.rev. São Paulo: Cortez, 2009.

RIZZINI, Irene at AL. Acolhendo crianças e adolescentes: experiências de promoção do direito à convivência familiar e comunitária no Brasil. São Paulo:

CORTEZ/UNICEF/CESPI/PUC-RJ, 2006.

SANTOS, Boaventura de Souza. A gramática do tempo: para uma nova cultura política. Coleção para um novo senso-comum, v. 4. São Paulo: Cortez, 2006.

SANTOS JÚNIOR, O.; AZEVEDO, S.; RIBEIRO, L. C. Q. Democracia e gestão local: a experiência dos conselhos municipais no Brasil. In: SANTOS JÚNIOR, O.; AZEVEDO, S.; RIBEIRO, L. C. Q (Orgs.). Governança democrática e poder local: a experiência dos conselhos municipais no Brasil. Rio de Janeiro: Revan Fase, 2004.

SARLET, Ingo Wolfgang. As dimensões da dignidade da pessoa humana: construindo uma compreensão jurídico-constitucional necessária e possível. Revista Brasileira de Direito Constitucional, n. 9, p. 361-388, jan./jun. 2007. Disponível em: 
http://www.esdc.com.br/seer/index.php/rbdc/article/view/137/131S. Acesso em: 25 nov. 2019.

SARLET, Ingo Wolfgang. A eficácia dos direitos fundamentais: uma teoria geral dos direitos fundamentais na perspectiva constitucional. 11. ed. Porto Alegre: Livraria do Advogado, 2012.

SZANIAWSKI, Elimar. Direitos de personalidade e sua tutela. São Paulo: Revista dos Tribunais, 2005.

SIMMEL, Georg. Sociologia: estudio sobre las formas de socialización. 5.ed. Madrid: Alianza, 1986.

SILVA, José Afonso da. Curso de Direito Constitucional Positivo. 32. ed. São Paulo: Malheiros Editores, 2009.

SILVA, Rosane Leal da. A proteção integral dos adolescentes internautas: limites e possibilidades em face dos riscos no ciberespaço. 2009. Tese (Doutorado em Direito) Faculdade de Direito. Universidade Federal de Santa Catarina, Florianópolis.

VIDAL, L. de F. A prática conselhista e a representação política: um estudo de caso sobre o Conselho Municipal dos Direitos da Criança e do Adolescente, Maringá. 2011. (Mestrado em Ciências Sociais) - Programa de Pós-Graduação em Ciências Sociais, Universidade Estadual de Maringá, Maringá, 2011.

VYGOTSKY, Lev Semyonovich. Pensamento e linguagem. São Paulo: Martins Fontes. 1993.

VERONESE, Josiane Rose Petry; RODRIGUES, Walkíria Machado. A figura da criança e do adolescente no contexto social: de vítimas a autores de ato infracional. Brasília: ABMP, 2001.

WALLON, Henri. A evolução psicológica da criança. Lisboa: Edições 70, 1968 